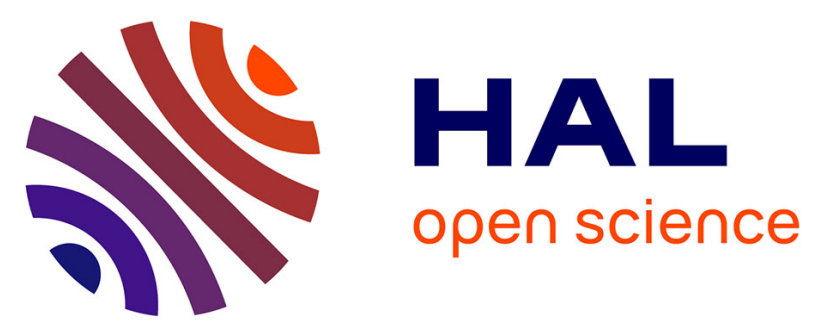

\title{
Analysis and interpretation of photo-stimulated discharge spectrum for polypropylene films under different electric and geometrical conditions
}

Peng Ma, Yewen Zhang, Stéphane Holé, Feihu Zheng, Min Gu, Zhenlian An

\section{- To cite this version:}

Peng Ma, Yewen Zhang, Stéphane Holé, Feihu Zheng, Min Gu, et al.. Analysis and interpretation of photo-stimulated discharge spectrum for polypropylene films under different electric and geometrical conditions. Journal of Electrostatics, 2016, 84, pp.128 - 134. 10.1016/j.elstat.2016.10.004 . hal01420195

\section{HAL Id: hal-01420195 \\ https://hal.sorbonne-universite.fr/hal-01420195}

Submitted on 20 Dec 2016

HAL is a multi-disciplinary open access archive for the deposit and dissemination of scientific research documents, whether they are published or not. The documents may come from teaching and research institutions in France or abroad, or from public or private research centers.
L'archive ouverte pluridisciplinaire HAL, est destinée au dépôt et à la diffusion de documents scientifiques de niveau recherche, publiés ou non, émanant des établissements d'enseignement et de recherche français ou étrangers, des laboratoires publics ou privés. 


\section{Analysis and interpretation of photo-stimulated discharge spectrum for polypropylene films under different electric and geometrical conditions}

Peng Ma ${ }^{2}$, Yewen Zhang ${ }^{1,2, a) *}$, Stéphane Holée ${ }^{1,3, b) *}$, Feihu Zheng ${ }^{1}$, Min Gu ${ }^{1}$ and Zhenlian An ${ }^{1}$

${ }^{1}$ Department of Electrical Engineering, Tongji University, Shanghai 201804, China

${ }^{2}$ Shanghai Key Laboratory of Special Artificial Microstructure Materials and Technology, Department of Physics, Tongji University, Shanghai 200092, China

${ }^{3}$ Laboratoire de Physique et d'Étude des Matériaux (LPEM, UMR 8213), CNRS, Sorbonne Universités, UPMC Univ Paris 06, PSL Research University, ESPCI-ParisTech, Paris 75005, France

Email: a) yewen.zhang@tongji.edu.cn; ${ }^{\text {b) }}$ stephane.hole@tongji.edu.cn 


\begin{abstract}
Experiments on polypropylene films under different electric and geometrical conditions are carried out to investigate various causes that would affect the interpretation of photo-stimulated discharge spectrum. The samples used in the experiment are metallized with finger-like shape or circular shape electrodes. The results show that the occurrence of photoemissions from electrode or polymer at wavelengths less than about $260 \mathrm{~nm}$ is possible, depending on the polarity and amplitude of applied voltage. The photocurrent spectra for samples with circular electrodes characterize two charge de-trapping peaks and the peak at $273 \mathrm{~nm}$ is also partially contributed by the photoelectrons from electrode.
\end{abstract}

Keywords: photo-stimulated discharge, space charge, trap depth, polypropylene, photoemission 


\section{Introduction}

Space charge accumulation affects the electrical properties of the polymeric insulation by distorting the electric field in the bulk. This can produce degradations and even premature breakdown for high-voltage applications [1-5]. Therefore, the suppression of charge buildup in insulating polymers has been a research focus for decades $[6,7]$. Modification of charge traps has been demonstrated to be an effective way to modulate the space charge formation and transportation in insulating polymeric materials. It was suggested that shallow and deep traps are formed respectively by the existence of physical defects (e.g. lamella-amorphous interface) and chemical defects (e.g. additives and byproducts) in polymers [8]. Though many kinds of techniques, e.g. thermal methods and optical methods, have been developed to measure the trap depths, experimental results remain scattered [9-12]. Among those methods, photo-stimulated discharge (PSD) method is a direct and powerful technique to obtain the charge trap depths in polymeric materials [10, 13-16]. Comparing to thermally stimulated discharge (TSD) method, PSD method detects much deeper traps without destroying the samples. In recent years, important advances have been made in understanding charge traps by PSD method. For example, Gonzalez et al demonstrated that only charges trapped in the deepest traps are responsible for the piezoelectric behavior by selective discharge of cellular polypropylene films [17]. Yue et al investigated the evolution of deep charge traps in polyimide under low-energy proton irradiation and found that the decrease of PSD intensities is due to the irradiation-induced degradation of carbonyl groups [18]. Based on PSD theory about release of charges from the mono- and multi-level of traps, Zhu et al proposed two modified data processing methods for more accurately obtaining the information of trapped charges [19].

However, PSD spectrum is induced not only by the de-trapping process of injected space charges but also by the photoemission from electrodes and polymer materials in practical experiments $[20,21]$. The photoemission process from the electrode is influenced by both the work function of the electrodes and the surface states of the polymers [22-24]. Photoemission from polymeric materials in UV wavelength is from the surface states of the sample [21, 25-27]. Because the work function of the illuminated electrode and the dielectric surface states are usually in the same photon energy range in PSD experiments, a comprehensive understanding of the photoemission mechanism from the illuminated electrode and dielectric surface is of great significance for correctly interpreting PSD spectra. However, up to now, photoemission mechanisms have seldom been studied in PSD measurements. When Takai et al. measured the PSD spectra for studying traps in $\gamma$-irradiated polyethylene, they observed a broad peak around $240 \mathrm{~nm}$ for which no explanations were given [15]. In our previous studies, 
some current peaks at short wavelengths $(240 \mathrm{~nm}$ and $300 \mathrm{~nm})$ cannot be interpretted by charge de-trapping mechanisms [28]. A strong photocurrent in the ultraviolet (UV) region has been observed and was suggested to originate from the photoelectric effect of the electrode, but no further evidences have been given [13, 29].

In this paper, photocurrent spectra for polypropylene films under different electric and geometrical conditions are studied. The samples with specifically deposited finger electrode are adopted to find out the origins of the photocurrent at different wavelengths and to confirm the electric conditions for generating these photocurrents. In order to identify the wavelength region of charge de-trapping current in the PSD spectra, a sample metalized with semi-transparent solid electrode is also tested during and after voltage applications and then their corresponding photocurrent spectra are compared.

\section{Experiment}
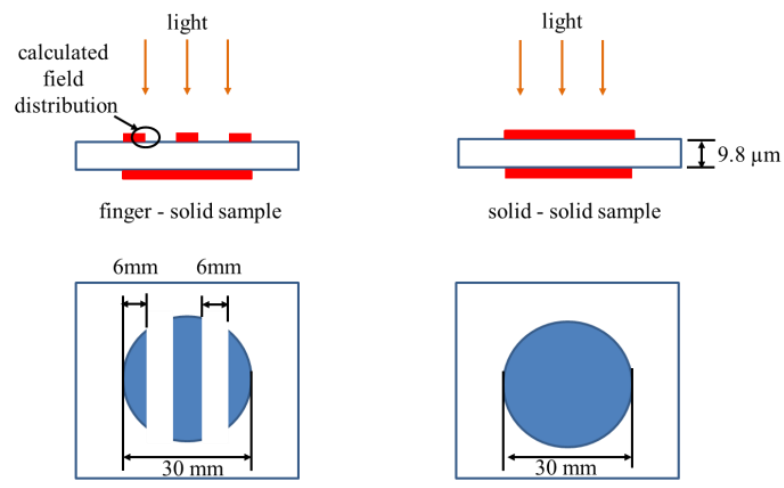

Figure 1. Sample geometry with either solid or finger electrodes. The electric field distribution in the indicated region is shown in figure 7.

The measurements are carried out on commercially available bi-axially oriented polypropylene films of $9.8 \mu \mathrm{m}$ thickness and $169^{\circ} \mathrm{C}$ melting point. The films are cut into $50 \times 50 \mathrm{~mm}^{2}$ square shapes. Gold (Au) or aluminum (Al) has been sputtered or evaporated in high vacuum on both sides of the sample as $30 \mathrm{~mm}$ diameter electrodes. Au electrode is semitransparent ( $20 \mathrm{~nm}$ thickness) and $\mathrm{Al}$ electrode is opaque (180 nm thickness). One kind of electrode has a circular shape (solid electrode) and the other kind has a finger-like shape (finger electrode). The samples with solid or finger electrodes are illustrated in figure 1. The samples are sandwiched by two plate copper electrodes of $30 \mathrm{~mm}$ diameter, one having a ring shape of $20 \mathrm{~mm}$ inner diameter in order to allow monochromatic light illuminating on the center of the sample. For short in the following, samples are named after their electrode combinations. For example, the sample with finger and solid Au respectively as front and back electrodes is called 
finger Au - solid Au sample.

The samples are illuminated with monochromatic light generated by a $450 \mathrm{~W}$ Xe arc lamp (Osram XBO 450/4) resolved by a monochromator (Dongwoo Optron DM-201i). The photocurrent is measured with a Keithley 6514 electrometer while the illuminating light scans from longer to shorter wavelengths. The bandwidth of the monochromatic light is $20 \mathrm{~nm}$ and the scanning rate is $24 \mathrm{~nm} / \mathrm{min}$. The details of the measurement setup can be found in previous publications $[19,30]$. The light illumination side is the front electrode and the photocurrent from the front electrode to the back electrode is taken as the positive current. The charging duration before the scanning measurement is 1 hour. Measurements are carried out in air in a double screen dark room at room temperature and with a relative humidity of about $55 \%$. Because the signal-to-noise ratio (SNR) of the output voltage from available positive voltage supply is not as good as that from negative voltage supply, we have used negative voltage supply as much as possible unless explicitly noted otherwise. The polarity reversal of the electric field in the sample is performed by connecting the negative voltage supply either to the front electrode or to the back electrode. The electrometer is then connected to the grounded electrode.

\section{Results and discussion}

The normalized current of a charged sample (photocurrent generated per incident photon on the sample surface) is used by many researchers to characterize the amount of charges de-trapped from their traps when illuminated by photons of a particular wavelength [17, 31]. However, our purpose is to find the possible processes involved in the experiment and to further distinguish the physical mechanisms from each other for different photocurrent peaks. Besides, the spectral energy distribution of Xe lamp has the same feature among different scanning measurements. Therefore, the original photocurrents under different electrical conditions can be directly compared to find the different causes of the peaks in the photocurrent spectra.

\subsection{Photocurrent spectra for samples with different electrode combinations}

Figure 2 shows the photocurrent spectra for samples with different electrode combinations, with the scanning wavelength in the UV region from $350 \mathrm{~nm}$ to $200 \mathrm{~nm}$. It can be seen that there is no obvious photocurrent of solid $\mathrm{Au}$ - solid Au sample when $-100 \mathrm{~V}$ is applied to either front or back electrodes. However, the photocurrent of finger $\mathrm{Au}$ - solid $\mathrm{Au}$ sample is different since almost no photocurrent is observed when $-100 \mathrm{~V}$ is applied to the back electrode whereas a large photocurrent peak is detected when $-100 \mathrm{~V}$ applied to the front electrode. The photocurrent peak features an extremum positioned at about $224 \mathrm{~nm}$ and a cutoff wavelength at about $260 \mathrm{~nm}$. 
Notice that considering the difference between finger and solid electrodes, the photocurrents must be generated from the edges of the finger electrode. Since accurate estimation of the peak cutoff is very difficult, the cutoff wavelength is here defined by the intersection of the linear interpolation of photocurrent falling edge with the baseline.

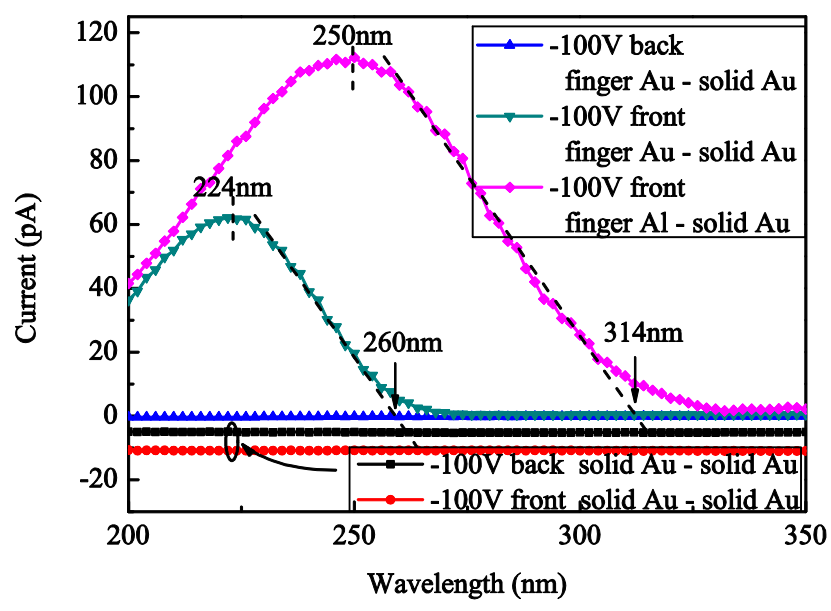

Figure 2. Comparison of photocurrent spectra for solid $\mathrm{Au}$ - solid $\mathrm{Au}$, finger $\mathrm{Au}$ - solid $\mathrm{Au}$ and finger $\mathrm{Al}$ - solid $\mathrm{Au}$ samples when $-100 \mathrm{~V}$ is applied to the front or the back electrode. The photocurrent spectra for solid $\mathrm{Au}-\mathrm{solid} \mathrm{Au}$ sample are vertically shifted to avoid overlapping.

In order to explain the large peak in the photocurrent spectra, the experiment is also carried out on finger $\mathrm{Al}$ solid Au sample. The position of the peak is shifted to the longer wavelengths compared with that from finger Au solid Au sample. The spectrum has its extremum and cutoff wavelength at about $250 \mathrm{~nm}$ and $290 \mathrm{~nm}$ respectively. The observed shift seems to be related to the different work functions of the electrode. Because the peak extremum is associated with both light source spectral energy distribution and quantum yield by light wavelength, the cutoff wavelength of the current peak is used to represent the relationship between the photocurrent response and the electrode work function.

There is a positive correlation between the peak cutoff wavelength and the electrode work function as shown in table 1. We thus speculate that the peak results from electron emission via photoelectric effect from the front finger electrode. However, the differences between the work function and the peak cutoffs of electrode $\mathrm{Au}$ and $\mathrm{Al}$ are also obvious, both being $0.33 \mathrm{eV}$. This difference may be caused by the monochromatic light bandwidth and the local electric field effect near the electrode edge in this experiment. The local electric field effect is verified by the experiments under different voltages in section 3.3. 
Table 1. Relationship between work function of the electrode material and photocurrent peak cutoff.

\begin{tabular}{ccc} 
electrode material & work function $(\mathrm{eV})[32]$ & cutoff $(\mathrm{nm}) /$ energy $(\mathrm{eV})$ \\
\hline $\mathrm{Au}$ & 5.1 & $260 / 4.77$ \\
$\mathrm{Al}$ & 4.28 & $314 / 3.95$ \\
\hline
\end{tabular}

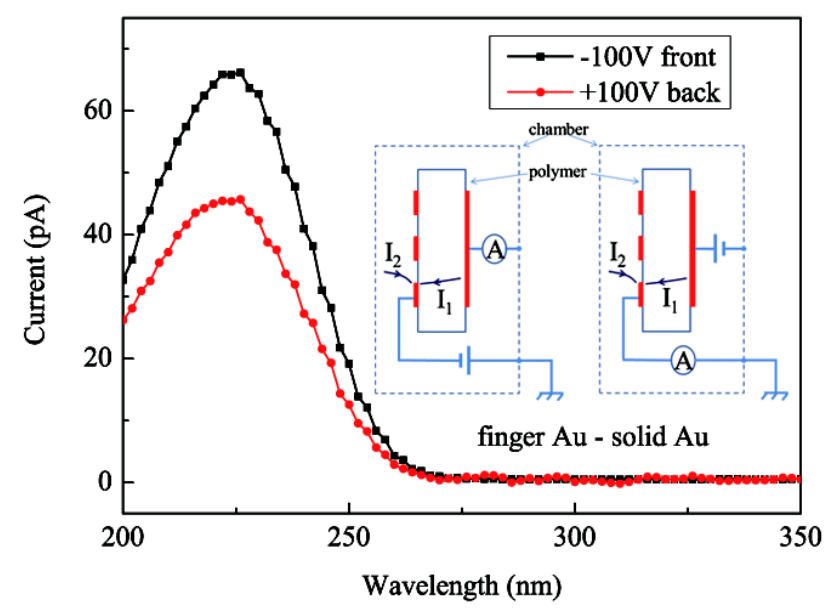

Figure 3. Comparison of photocurrent spectra when $-100 \mathrm{~V}$ is applied to the front electrode and $+100 \mathrm{~V}$ is applied to the back electrode. The inset shows the two possibilities of current routes in the experiment.

There are two possible routes for the current flow from front electrode to the chamber wall or to the polymer material [33] as shown in the inset of figure 3. To check the route of the photocurrent, the measurement is carried out twice. For the first measurement, the electrometer is connected to the back electrode and $-100 \mathrm{~V}$ voltage is applied to the front electrode. For the second measurement, the electrometer is connected to the front electrode and $+100 \mathrm{~V}$ voltage is applied to the back electrode. As the electrode field in the sample is same in the two cases, if there is part of the current flowing to the chamber wall, the amplitude of the current in the first measurement should be smaller than that in the second measurement. The results are shown in figure 3 . It can be seen that the shape of photocurrent spectra is almost the same and the amplitude of the current in the first measurement is even larger than that in the second measurement. This shows that, if the current from the electrode to the chamber wall exists, it is not the main contribution to the measured current under the UV light illumination. Additional experiments show that amplitude slightly reduces from one measurement to the following. This phenomenon can be explained by the electric field shielding effect as demonstrated in the next section. 


\subsection{Evolution of photocurrent spectra for long time UV illumination measurement}

In order to find the reason for the amplitude decrease phenomenon in two successive measurements, a new finger $\mathrm{Au}$ - solid Au sample is used to carry out long time illumination experiments. The negative voltage $-100 \mathrm{~V}$ is applied to the front electrode. Experimental procedures are as shown in figure 4. First, the sample is illuminated by monochromatic light at $224 \mathrm{~nm}$ for one hour without voltage application (between $\mathrm{t}_{0}$ and $\mathrm{t}_{1}$ as shown in figure 4). Second, the photocurrent spectrum is measured after one hour voltage application (denoted as "the 1st scanning", between $t_{2}$ and $t_{3}$ ). Third, the sample is illuminated under $224 \mathrm{~nm}$ monochromatic light with the voltage on for about 50 minutes. Then the photocurrent spectrum is measured for the second time after the voltage being applied for another one hour (denoted as "the 2 nd scanning", between $t_{5}$ and $t_{6}$ ). Last, the sample is thermally treated under short-circuit at $353 \mathrm{~K}$ for 4 hours and then the photocurrent spectra are measured for the third time after one hour voltage application (denoted as "the 3rd scanning", between $t_{8}$ and $t_{9}$ ).

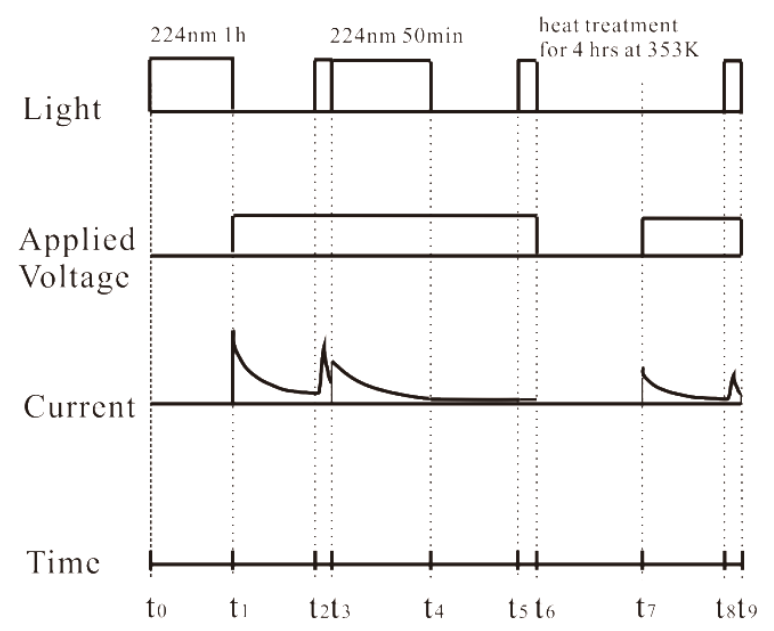

Figure 4. Procedure for the measurement when $-100 \mathrm{~V}$ is applied to the front electrode of the sample. Time $t_{0}$ and $\mathrm{t}_{3}$ : monochromatic light on; Time $\mathrm{t}_{1}$ and $\mathrm{t}_{7}$ : voltage on; Time $\mathrm{t}_{2}, \mathrm{t}_{5}$ and $\mathrm{t}_{8}$ : light scanning started; Time $\mathrm{t}_{4}, \mathrm{t}_{6}$ : light off; Time t9: voltage off and light off.

The experimental results are shown in figure 5. The photocurrent gradually decreased to $1 \mathrm{pA}$ with the monochromatic illumination at $224 \mathrm{~nm}$ for 50 minutes, as shown in the inset of figure 5. A first assumption is that 50 minutes illumination at $224 \mathrm{~nm}$ may affect the film electrical property so as to induce the photocurrent decrease. Because the photocurrent spectrum for the 1st scanning is almost the same as the spectrum for the sample without enduring long time illumination (as shown in figure 3), this assumption is excluded. As mentioned above, the photoemission electrons from the electrode move toward the film. Then some charges can accumulate 
in polypropylene near the finger edge under the light illumination. Accordingly, the applied electric field near the edge is counter balanced by the local electric field from the accumulated charges. When the total electric field goes under a threshold value, the photoemission process can be tremendously weakened. Therefore, we assume that space charge shielding effect causes the decrease of the photocurrent under long time illumination. It can be seen that, even though there is one hour duration between the third step and the 2nd scanning, the current detected at $224 \mathrm{~nm}$ remains very low, about $1 \mathrm{pA}$. This indicates that the accumulated photoemission charges are very stable at room temperature. However, the photocurrent spectrum is partially recovered after the 4 hours heat treatment on the sample. It is reasonable to assume that accumulated charges move away from their positon, thus the amplitude of the shielding field weakens accordingly. Consequently, photoemissions from the electrode can be observed again in the 3rd scanning.

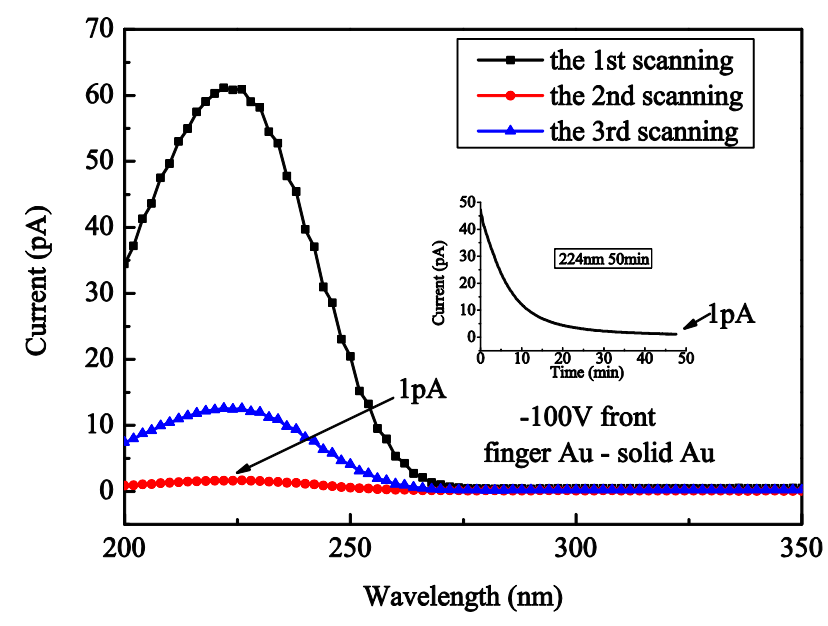

Figure 5. Evolution of photocurrent spectra due to long time monochromatic illumination at $224 \mathrm{~nm}$ when $-100 \mathrm{~V}$ is applied to the front electrode. The inset shows the decrease of photocurrent with time under the illumination.

\subsection{Comparison of photocurrent spectra under different voltages}

Based on the above analysis, space charge accumulation occurs in polypropylene film under UV illumination but their positions are still to elucidate. Moreover, charge emission from electrode edge to polymer has also been reported without UV illumination by many researchers by using surface potential measurement [34, 35]. Therefore, electric field emission from electrode can contribute along with photoemission to the measured results. In order to further understand the experimental results, experiments in a wide range of voltage levels $(5 \mathrm{~V}, 15 \mathrm{~V}, 30 \mathrm{~V}, 100 \mathrm{~V}$, $300 \mathrm{~V}, 500 \mathrm{~V}$ and $700 \mathrm{~V}$ ) are carried out. Finger Au - solid Au samples are used in these experiments. First, a negative voltage is applied to the back electrode of the sample for one hour and then the photocurrent spectrum is 
measured. Second, the photocurrent spectrum is measured again after short-circuiting the sample 15 min in the dark. This experimental procedure is repeated when negative voltage is applied to the front electrode. For each measurement at different voltage levels, a new sample is used to avoid the effect of the remnant charges on the experimental results.

Figure 6(a) shows the photocurrent spectra when voltage from $-5 \mathrm{~V}$ to $-700 \mathrm{~V}$ is applied to the back electrode of the sample. Almost no photocurrent response is observed when the voltage amplitude is smaller than $100 \mathrm{~V}$ and the photocurrent gradually increases with the voltage amplitude above $300 \mathrm{~V}$. Moreover, it can also be observed that the amplitude of each spectrum increases with the increase of photon energy up to about $210 \mathrm{~nm}$. However, it seems that the photocurrent features a much steeper increase when the wavelength is shorter than about $250 \mathrm{~nm}$. Thus, the photocurrent below and above $250 \mathrm{~nm}$ must be involved in different charge migration mechanisms.

Considering the polarity of the measured current, two possibilities, i.e. photoemission from the back electrode and photoemission from polypropylene surface between the finger electrodes, can cause the photocurrent spectrum in the region below $250 \mathrm{~nm}$. First, the current is generated by the photoemission from the back electrode. But the peak cutoff of the photocurrent is not at $260 \mathrm{~nm}$ as expected, which may be caused by the optical absorption spectrum of the polypropylene film. An inversed sample with finger electrode at the back side (solid $\mathrm{Au}$ - finger $\mathrm{Au}$ sample) is used to test that former possibility. For comparison, the back plate copper electrode used in this experiment also has a ring shape. The experimental results are shown in the inset of figure 6(a). It can be seen that the cutoff of the peak is the same as that measured when the front electrode is fingered. Therefore, it can be assumed that the photoemission from the surface states of polypropylene between the finger electrodes accounts for the photocurrent in the wavelength region below $250 \mathrm{~nm}$. The surface states are formed due to the surface features of polymer film like the topological roughness, residues, and polymer oxidation etc [36]. Murata has also reported photoemission phenomena from surface states of polymers when he studied the effect of surface charging on surface states by using UV illumination measurement [25]. The associated mechanisms of photocurrent spectra above $250 \mathrm{~nm}$ will be discussed later. 

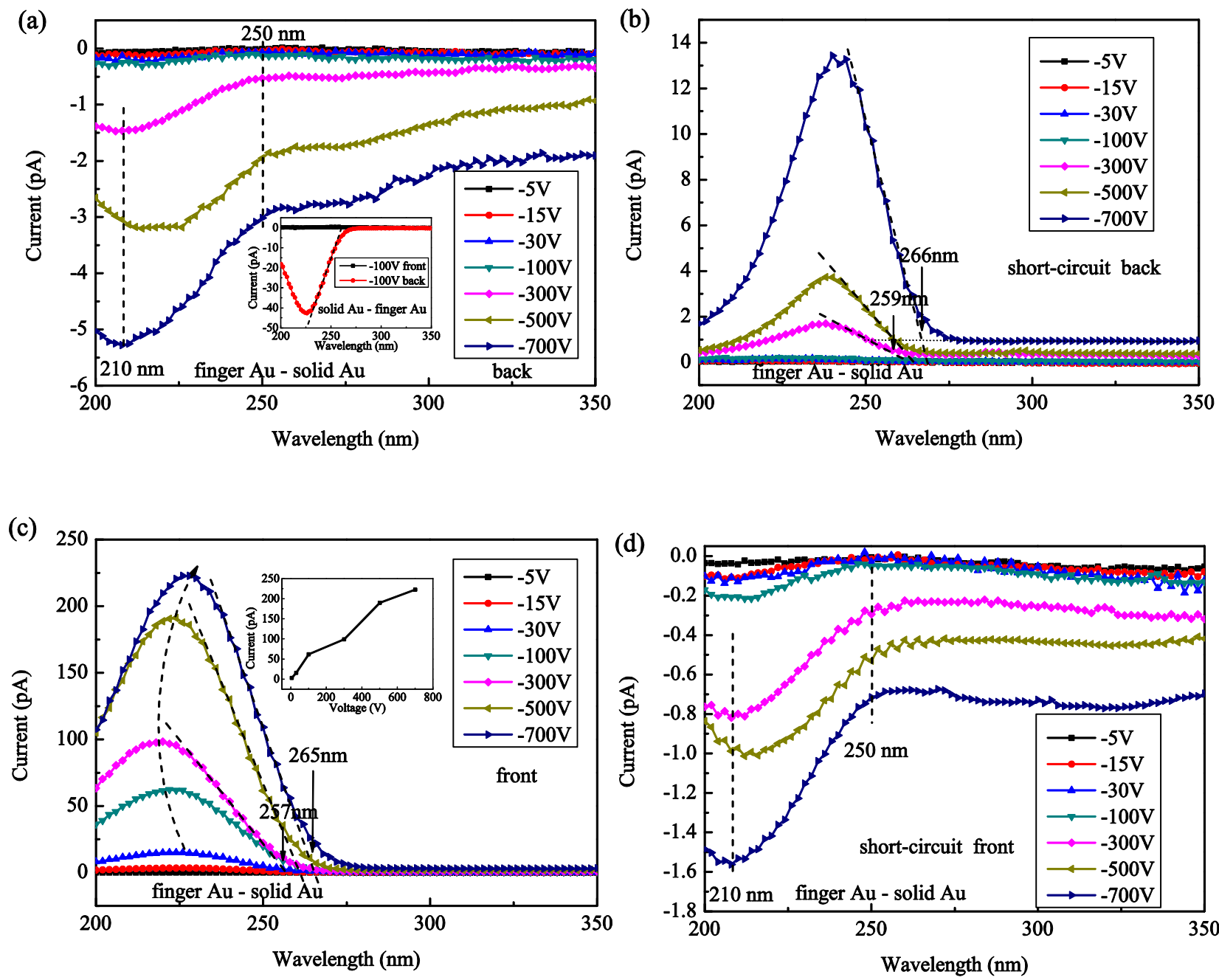

Figure 6. Comparison of photocurrent spectra for samples (a) when a negative voltage is applied to the back electrode, (b) after the removal of a negative voltage from the back electrode, (c) when a negative voltage is applied to the front electrode, and (d) after the removal of the negative voltage from the front electrode. The inset of figure 6 (a) shows the photocurrent spectra for solid Au - finger Au sample, and the inset of figure 6 (c) shows the dependence of peak amplitude on the applied voltage.

The short-circuit photocurrent spectra measured after the removal of the voltage are as shown in figure 6(b). An obvious peak with a cutoff wavelength from about $259 \mathrm{~nm}$ to $266 \mathrm{~nm}$ is visible from the photocurrent spectra for samples that have been pre-charged under voltage above $300 \mathrm{~V}$ amplitude. There is no response in the photocurrent spectra for samples under voltage below $100 \mathrm{~V}$ amplitude. It can be noticed that the cutoff wavelength is almost the same than the one obtained under $-100 \mathrm{~V}$ applied to the front electrode (as shown in figure 3). It can be speculated that positive charges accumulate in polypropylene near the finger electrode edge during the 1st step and thus a local positive electric field builds up. Therefore, photoelectrons are generated from 
the electrode edge if the local electric field is strong enough. However, the position of photocurrent extremum is about $240 \mathrm{~nm}$ which is $16 \mathrm{~nm}$ larger than that measured under $-100 \mathrm{~V}$ applied to the front electrode. One possibility is that the peak with lower amplitude may be more easily influenced by the photoemission electrons from polymer which forms a reverse current, and the measured photocurrent is the photoemission current from electrode superimposed by the photoemission current from the polymer. But the spectrum measured under $-30 \mathrm{~V}$ applied to the front electrode has almost the same amplitude, and has no wavelength shift as shown in figure 6(c). Another possibility is that accumulated positive charges can be partially recombined by the electrons from the electrode during the scanning process. Accordingly, local electric field near the electrode edge weakens and so does the photoemission current amplitude at the shorter wavelengths. This results in a measured photocurrent peak with a shift toward longer wavelengths compared to photocurrents measured under $-100 \mathrm{~V}$. A question arises as to what physical mechanism accounts for the generation of the accumulated charges? They can come from field emission from electrode due to one hour high voltage application [34] and/or from the photoemission from the polymer during the UV illumination at the beginning of the procedure. We have carried out experiments on the sample without UV scanning measurement during the voltage application but a similar photocurrent peak is also observed during the short-circuit measurements. This indicates that field emission from finger electrode can also produce amounts of charges which finally generate a strong local electric field.

Figure 6(c) shows the photoemission current when a voltage from $-5 \mathrm{~V}$ to $-700 \mathrm{~V}$ is applied to the front electrode of the sample. The current peak slowly increases with the voltage amplitude, while the extremum position firstly slightly shifts to shorter wavelengths when the voltage goes from $-30 \mathrm{~V}$ to $-300 \mathrm{~V}$ and then shifts inversely to longer wavelengths when the voltage amplitude increases further. If electrons were generated just by the photoelectric effect, there should be a saturation of the photocurrent with the increase of applied voltage. However, the inset of figure 6(c) does not show a saturation. Therefore, a field-assisted photoelectric emission mechanism can be expected, especially when higher voltage amplitude is applied [37]. In addition, the existence of field-assisted photoemission can illustrate the longer-wavelength-direction shift of the photocurrent peak when the voltage amplitude increases from $300 \mathrm{~V}$ to $700 \mathrm{~V}$ (cutoffs from $257 \mathrm{~nm}$ to $265 \mathrm{~nm}$ ). Indeed, electrons can be emitted from the electrode by photons with less energy under higher electric field. It can be noticed that the cutoff wavelengths under different voltages are in the same range as that in figure6 (b). However, the shorter-wavelength-direction shift of the photocurrent peak at lower voltage from $-30 \mathrm{~V}$ to $-300 \mathrm{~V}$ is more difficult to understand. Here, a tentative explanation is given on the basis of charge shielding effect. Under very low 
voltages $(-5 \mathrm{~V}$ to $-30 \mathrm{~V})$, the charge shielding effect is negligible because almost no accumulated charges exist near the electrode edge. Thus the peak position is not influenced. When the voltage is increased (-100 V to $-300 \mathrm{~V}$ ), charges accumulate in polypropylene film and produce a large shielding field compared with the applied electric field. Thus charges reduce the photoemission from the electrode. Therefore, the photocurrent peak between $-100 \mathrm{~V}$ and $-300 \mathrm{~V}$ is slightly shifted to shorter wavelengths.

Figure 6(d) shows similar photocurrent spectra as those shown in figure 6(a). A steep increase can also be observed when the wavelength is below about $250 \mathrm{~nm}$. As in figure 6(b), negative charges can also have accumulated in polypropylene film. This forms similar local negative electric field near the finger electrode edge. Therefore, the photocurrent at the wavelength shorter than $250 \mathrm{~nm}$ in these spectra results from the photoemission from polypropylene. A very broad peak can be observed above $250 \mathrm{~nm}$, which may be associated with the photoconduction current. It has to be pointed out that the current above $250 \mathrm{~nm}$ is so low (about $0.4 \mathrm{pA}$ ) that it is difficult to notice it when measuring slightly large currents (e.g. figure 6(b) and (c)). For avoiding the disturbance from finger electrode edge, the current in the region above $250 \mathrm{~nm}$ is studied further by using solid $\mathrm{Au}$ - solid $\mathrm{Au}$ sample in section 3.4 .
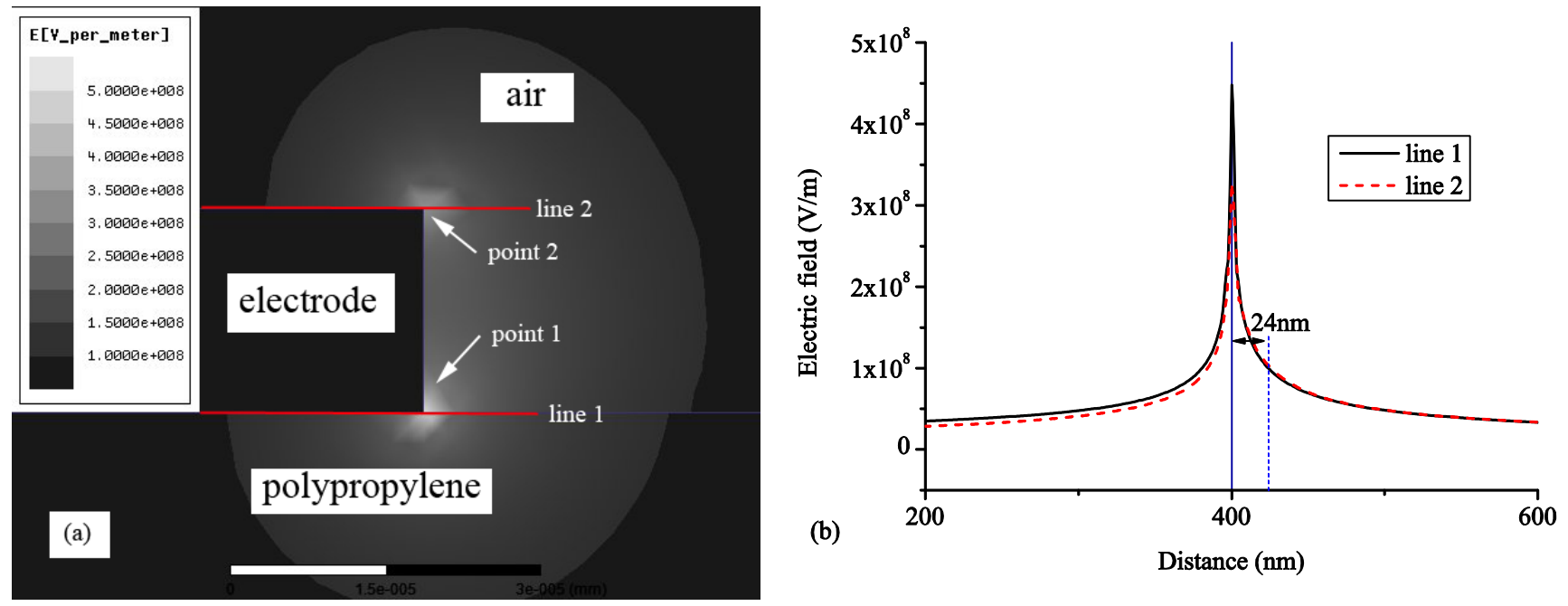

Figure 7. Electric field distribution near the finger electrode edge (a) in two dimensions and (b) along line 1 and line 2 when the finger $\mathrm{Au}$ - solid $\mathrm{Au}$ sample is under voltage $100 \mathrm{~V}$. Point 1 and point 2 are the electrode tips in the paper plane and line 1 and line 2 are two lines passing through the two points.

It is quite obvious that the strong field emission and the photoemission from the electrode come from the electric field distortion at the finger electrode edge. Ansoft Maxwell, which is a powerful tool for electromagnetic field simulation, is used to model the electric field distribution. Space charge accumulation in the film or near the 
finger electrode edge is not taken into account in the modeling process to simplify the numerical simulations. Here, the results are focused in the region indicated in the top left of figure 1. Figure 7(a) and (b) show the simulation when $100 \mathrm{~V}$ is applied to the back electrode in the experiment. Two regions exhibit strong electric field distortion near point 1 and point 2 as shown in figure 7(a). Line 1 and line 2 are parallel to the polypropylene surface and electrode edges and pass to point 1 and point 2, respectively. To have a clear view of the field distribution, the field strength along line 1 and line 2 is plotted in figure 7(b). It can be seen that the field strength at point 1 and point 2 is much higher than the average field strength in the film bulk $\left(1 \times 10^{7} \mathrm{~V} / \mathrm{m}\right)$. At $24 \mathrm{~nm}$ distance from both point 1 and 2, the electric field strength is still about 10 times higher than the average field strength. The photoemission process from polypropylene probably happens near point 1 and the field emission and the photoemission from the electrode can happen both at point 1 and point 2 .

Because the band gap of polymeric insulating material is usually above $8 \mathrm{eV}$ [8], photoemission due to interband transition of polypropylene is excluded. Based on the above discussions, it can be assumed that the electrons trapped in the surface states of polypropylene can contribute to the photoemission current in the wavelength region below $250 \mathrm{~nm}$ only if a local strong negative electric field is formed near the edge of finger electrode. Photoemission from the electrode happens under a local strong positive electric field near the edge of finger electrode and is affected by both the electrode work function and the local electric field. The charged surface states region can extend to a certain distance along the film surface from the finger electrode edge because of the migration of charges under their own electric field. If the photoelectron accumulation locates in the bulk of the film, the current above the wavelength $250 \mathrm{~nm}$ in figure 6(d) should be much larger than that measured in the experiment. Hence, most accumulated charges should just be trapped in the surface states of polypropylene near finger electrode edges, which accounts for the formation of large shielding field. The photocurrent above $250 \mathrm{~nm}$ is due to either the photoemission from electrodes or the de-trapping process of trapped charges, which will be discussed below. 


\subsection{Photocurrent spectra for solid Au - solid Au sample}

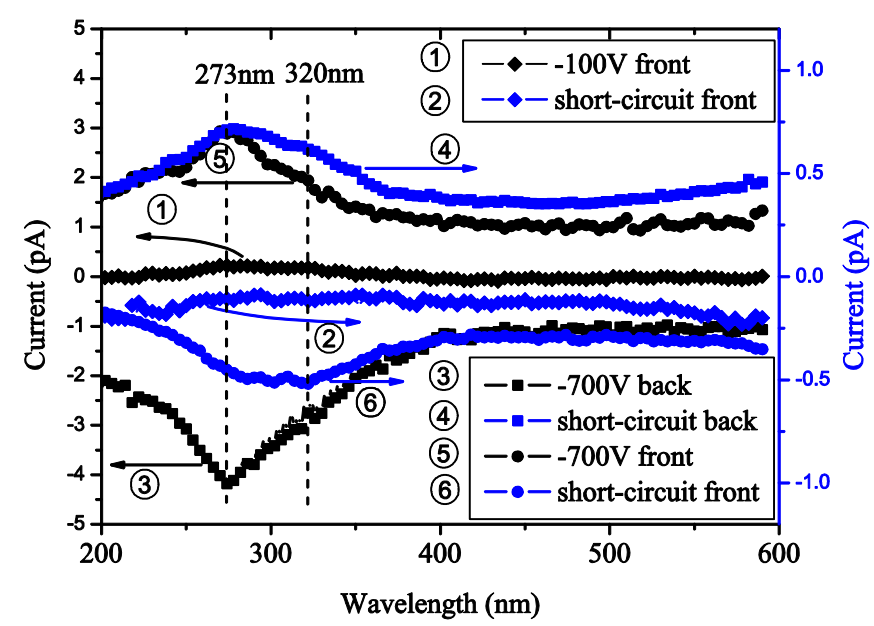

Figure 8. Photo-stimulated discharge spectra for the solid Au - solid Au sample.

For investigating the mechanisms of the current above $250 \mathrm{~nm}$ shown in figure 6(a) and (d), solid Au - solid Au samples have been used to carry out measurements during or after the application of $100 \mathrm{~V}$ and $700 \mathrm{~V}$. Because the broad peak in figure $6(\mathrm{~d})$ seems to extend on wavelengths above $350 \mathrm{~nm}$, the experiments are carried out from $600 \mathrm{~nm}$ to $200 \mathrm{~nm}$.

As shown in figure 8, the obvious photoemission current peak is absent in all spectra when solid Au solid Au samples are used. Almost no photocurrent peaks are observed in the measurements during or after the application of $100 \mathrm{~V}$ (curves 1 and 2). This indicates that no charges have accumulated in the film. However, two photoconduction current peaks at $273 \mathrm{~nm}$ and $320 \mathrm{~nm}$ are observed when $-700 \mathrm{~V}$ is applied (curves 3 to 6 ). Because surface states are tremendously diminished when solid electrodes are used [38], the two current peaks should be related to accumulated charges in the bulk of the film. It has been reported that homo space charges accumulate in polypropylene film measured by thermal pulse (TP) method [39]. Therefore, there also exists field shielding effect from the bulk charges when the sample is under high voltage, though there is no large electric field distortion without finger electrodes. Accordingly, the electric field strength can then be greatly depressed at the interface between the electrode and the polypropylene film.

Based on the above discussion, it is likely that photoemission from the electrode is impossible to occur. We then assume that the photocurrent peaks at $320 \mathrm{~nm}$ and $273 \mathrm{~nm}$ are both caused by the de-trapping process of the photo-stimulated charges. Because there is a discharge of the sample after the voltage removal, the amplitude of 
the photo-stimulated de-trapping current is smaller when the sample is under short-circuit than when it is under applied voltage as shown in figure 8 . Because there is a positive correlation between the amplitude of the charge de-trapping current and the amount of space charges stored in the film, the ratio between the de-trapping current amplitudes at $273 \mathrm{~nm}$ and $320 \mathrm{~nm}$ in the spectra can be seen as the relative quantity index of charges in deeper and shallower traps in a sample. The ratio between the two peak amplitudes for one sample should be the same whenever the sample is either under applied voltage or in short-circuit. Even considering different lifetimes of charges for deeper and shallower traps, the ratio of the spectra in the short-circuit measurements (curves 4 and 6) should be larger because of the relative faster decay rate of charges in $320 \mathrm{~nm}$ traps [30]. But the experimental results in figure 8 do not confirm this view. The only explanation is that photoelectrons from electrodes partially contribute to the peak at $273 \mathrm{~nm}$. Of course, the photoemission from polymer is also possible, but it is not considered here because the wavelength region below $250 \mathrm{~nm}$ has not obvious photocurrent peak. In conclusion, the current peak at $320 \mathrm{~nm}$ is certainly due to charge de-trapping mechanism and the current peak at $273 \mathrm{~nm}$ is certainly due to the combined contributions of charge de-trapping and photoemission from electrode.

\section{Conclusion}

The photocurrent spectra for samples under different electric and geometrical conditions have been compared in this paper. When a local strong positive electric field exists near the finger electrode, photoemission from finger electrode is observed. The generated electrons migrate to the polypropylene film and are partially captured by the surface states of polymer to form a stable charge accumulation near the finger electrode edge. The continued accumulation of charges can gradually increase the shielding field and finally inhibit the subsequent photoemission process. When a local large negative electric field is formed near the finger electrode, photoemission from surface states of polypropylene can be observed, with a cutoff wavelength at about $250 \mathrm{~nm}$.

An obvious photoconduction of polypropylene film can be observed in the wavelength region above $250 \mathrm{~nm}$ under high electric field. The measured current spectrum includes photoemission current from the electrode and the charge de-trapping current in polypropylene film. The photoconduction current peaks at $273 \mathrm{~nm}$ and $320 \mathrm{~nm}$ are mainly induced by de-trapping charges and the peak at $273 \mathrm{~nm}$ is also partially contributed by the photoelectrons from the electrode. 


\section{Acknowledgments}

We gratefully acknowledge the financial support from the National Natural Science Foundation of China (NSFC Nos. 51477118 and 51277133) and PhD Programs Foundation of Ministry of Education of China (No. 20130072110046). 


\section{REFERENCES}

[1] Qiao, B.; Teyssedre, G.; Laurent, C. J. Phys. D: Appl. Phys. 2015, 48, 405102.

[2] Dissado, L. A.; Mazzanti G.; Montanari, G. C. IEEE Trans. Dielectr. Electr. Insul. 2001, 8, 959.

[3] Zhang, Y.; Lewiner, J.; Alquie, C.; Hanpton N. IEEE Trans. Electr. Insul. 1996, 3, 778.

[4] Holé, S.; Ditchi, T.; Lewiner, J. IEEE Trans. Dielectr. Electr. Insul. 2003, 10, 670.

[5] Zheng, F.; Gu, M.; Dong, J.; An, Z.; Lei, Q.; Zhang, Y. J. Appl. Polym. Sci. 2015, 132, 42235.

[6] Tanaka, T. IEEE Trans. Dielectr. Electr. Insul. 2005, 12, 914.

[7] Wu, Y.; Zha, J.; Li, W.; Wang, S.; Dang, Z. Appl. Phys. Lett. 2015, 107, 112901.

[8] Teyssedre G.; Laurent, C. IEEE Trans. Dielectr. Electr. Insul. 2005, 12, 857.

[9] Liufu, D.; Kao, K. C. J. Appl. Phys. 1999, 85, 1089.

[10] Brodribb, J. D.; O'Colmain, D.; Hughes, D. M. J. Phys. D: Appl. Phys. 1975, 8, 856.

[11] Tian, F.; Bu, W.; Shi, L.; Yang, C.; Wang, Y.; Lei, Q. J. Electrost. 2011, 69, 7.

[12] Shen, W.; Mu, H.; Zhang, G.; Deng, J.; Tu, D. J. Appl. Phys. 2013, 113, 083706.

[13] Mellinger, A.; Gonzalez, F. C.; Gerhard-Multhaupt, R. IEEE Trans. Dielectr. Electr. Insul. 2004, 11, 218.

[14] Zhu, Z.; Zhang, Y.; An, Z.; Zheng, F. Acta Phys. Sin-Ch. Ed. 2012, 61, 067701.

[15] Takai, Y.; Mori, K.; Mizutani, T.; Ieda, M. Jpn. J. Appl. Phys. 1976, 15, 2341.

[16] He, L.; Chen, Y.; Dai, L.; Zhang, Y.; Zhao, L.; Cao, J.; Wang X.; Lei Q. ICPADM'09, (Piscataway, USA) pp. 1102 -1105 .

[17] Mellinger, A.; Gonzalez F. C.; Gerhard-Multhaupt, R. Appl. Phys. Lett. 2003, 82, 254.

[18] Yue, L.; Wang, X.; Wu, Y.; Cao, J.; Liu, Y.; Sun, C.; Yang, J. J. Phys. D: Appl. Phys. 2013, 46, 145502.

[19] Zhu, Z.; Zhang, Y.; An, Z.; Zheng, F. Meas. Sci. Technol. 2011, 22, 085109.

[20] Tetsuji, O.; Tomoaki, U.; Genso, M. 6 th ISE ( Oxford , UK), pp. 142 - 146.

[21] Murata, Y.; Hiyoshi, I. Jpn. J. Appl. Phys. 1997, 36, 5329.

[22] Takai, Y.; Osawa, T.; Kwan Chi, K.; Mizutani, T.; Ieda, M. Jpn. J. Appl. Phys. 1975, 14, 473.

[23] Tahira, K. ; Kao, K. C. J. Phys. D: Appl. Phys. 1985, 18, 2247.

[24] Kan, L.; Kao, K. C. J. Chem. Phys. 1993, 98, 3445.

[25] Murata, Y. Jpn. J. Appl. Phys. 1979, 18, 1.

[26] Hashimoto, Y. Electr. Eng. Jpn. 2014, 188, 9.

[27] Hegeler, F.; Krompholz, H. G.; Hatfield, L. L.; Kristiansen, M. IEEE Trans. Plasma Sci 1997, 25, 300.

[28] Ma, P.; Zhang, Y.; Zheng, F.; An, Z.; Lei, Q. Europhys. Lett. 2015, 109, 27006. 
[29] Kan, L.; Kao, K. C. presented at ISEI, (New York, USA) pp. 84 - 87.

[30] Ma, P.; Zhang, Y.; Zheng, F.; An, Z. ICSD’13, (Piscataway, USA) pp. 768 - 771.

[31] Suzuoki, Y.; Mizutani, T.; Takai, Y.; Ieda, M. Jpn. J. Appl. Phys. 1977, 16, 1929.

[32] Michaelson, H. B. J. Appl. Phys. 1977, 48, 4729.

[33] Wintle, H. J. IEEE Trans. Electr. Insul. 1977, 12, 97.

[34] Atkinson, P. J.; Fleming, R. J. J. Phys. D: Appl. Phys. 1976, 9, 2027 .

[35] Pepin, M. P.; Wintle, H. J. J. Appl. Phys. 1998, 83, 5870.

[36] Taleb, M.; Teyssedre, G.; Le Roy, S.; Laurent, C. IEEE Trans. Dielectr. Electr. Insul. 2013, 20, 311.

[37] Yang, H.; Chen, S.; Xu, T.; Yu, H.; Xie X.; Li, R. Optik 2008, 119, 180.

[38] An, Z.; Cang, J.; Chen, X.; Zheng, F.; Zhang, Y. IEEE Trans. Dielectr. Electr. Insul. 2013, 20, 329.

[39] Zheng, F.; Liu, C.; Lin, C.; An, Z.; Lei, Q.; Zhang, Y. Meas. Sci. Technol. 2013, 24, 065603. 


\section{FIGURE CAPTIONS}

Figure 1. Sample geometry with either solid or finger electrodes. The electric field distribution in the indicated region is shown in figure 7.

Figure 2. Comparison of photocurrent spectra for solid $\mathrm{Au}$ - solid $\mathrm{Au}$, finger $\mathrm{Au}$ - solid $\mathrm{Au}$ and finger $\mathrm{Al}$ - solid $\mathrm{Au}$ samples when $-100 \mathrm{~V}$ is applied to the front or the back electrode. The photocurrent spectra for solid $\mathrm{Au}$ - solid $\mathrm{Au}$ sample are vertically shifted to avoid overlapping.

Figure 3. Comparison of photocurrent spectra when $-100 \mathrm{~V}$ is applied to the front electrode and $+100 \mathrm{~V}$ is applied to the back electrode. The inset shows the two possibilities of current routes in the experiment.

Figure 4. Procedure for the measurement when $-100 \mathrm{~V}$ is applied to the front electrode of the sample. Time $t_{0}$ and $\mathrm{t}_{3}$ : monochromatic light on; Time $\mathrm{t}_{1}$ and $\mathrm{t}_{7}$ : voltage on; Time $\mathrm{t}_{2}, \mathrm{t}_{5}$ and $\mathrm{t}_{8}$ : light scanning started; Time $\mathrm{t}_{4}, \mathrm{t}_{6}$ : light off; Time t9: voltage off and light off.

Figure 5. Evolution of photocurrent spectra due to long time monochromatic illumination at $224 \mathrm{~nm}$ when $-100 \mathrm{~V}$ is applied to the front electrode. The inset shows the decrease of photocurrent with time under the illumination.

Figure 6. Comparison of photocurrent spectra for samples (a) when a negative voltage is applied to the back electrode, (b) after the removal of a negative voltage from the back electrode, (c) when a negative voltage is applied to the front electrode, and (d) after the removal of the negative voltage from the front electrode. The inset of figure6 (a) shows the photocurrent spectra for solid Au - finger Au sample, and the inset of figure6 (c) shows the dependence of peak amplitude on the applied voltage.

Figure 7. Electric field distribution near the finger electrode edge (a) in two dimensions and (b) along line 1 and line 2 when the finger $\mathrm{Au}$ - solid Au sample is under voltage $100 \mathrm{~V}$. Point 1 and point 2 are the electrode tips in the paper plane and line 1 and line 2 are two lines passing through the two points.

Figure 8. Photo-stimulated discharge spectra for the solid Au - solid Au sample. 
Table 1. Relationship between work function of the electrode material and photocurrent peak cutoff. electrode material work function $(\mathrm{eV})[32]$ cutoff $(\mathrm{nm}) / \mathrm{energy}(\mathrm{eV})$

$\mathrm{Au}$

5.1

$260 / 4.77$

$\mathrm{Al}$

4.28

$314 / 3.95$ 


\section{Figure 1.}

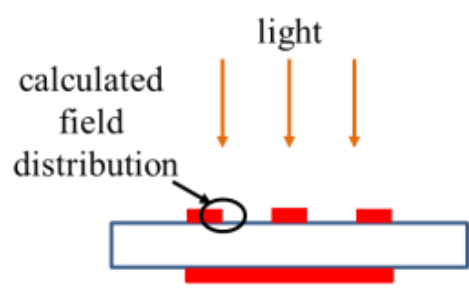

finger - solid sample

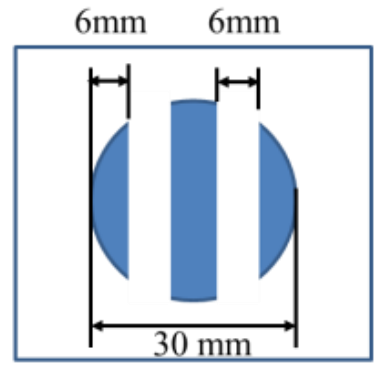

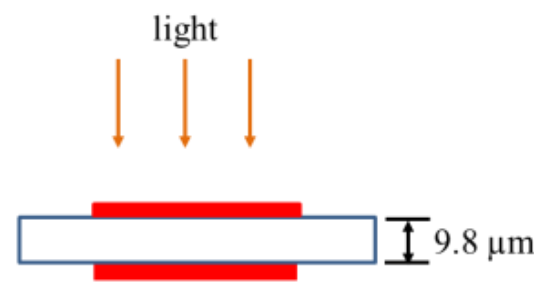

solid - solid sample

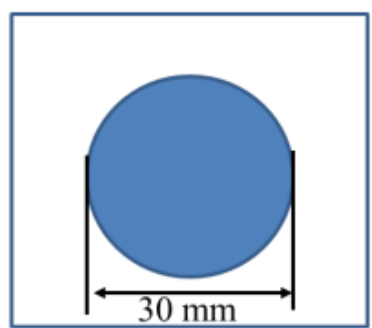




\section{Figure 2.}

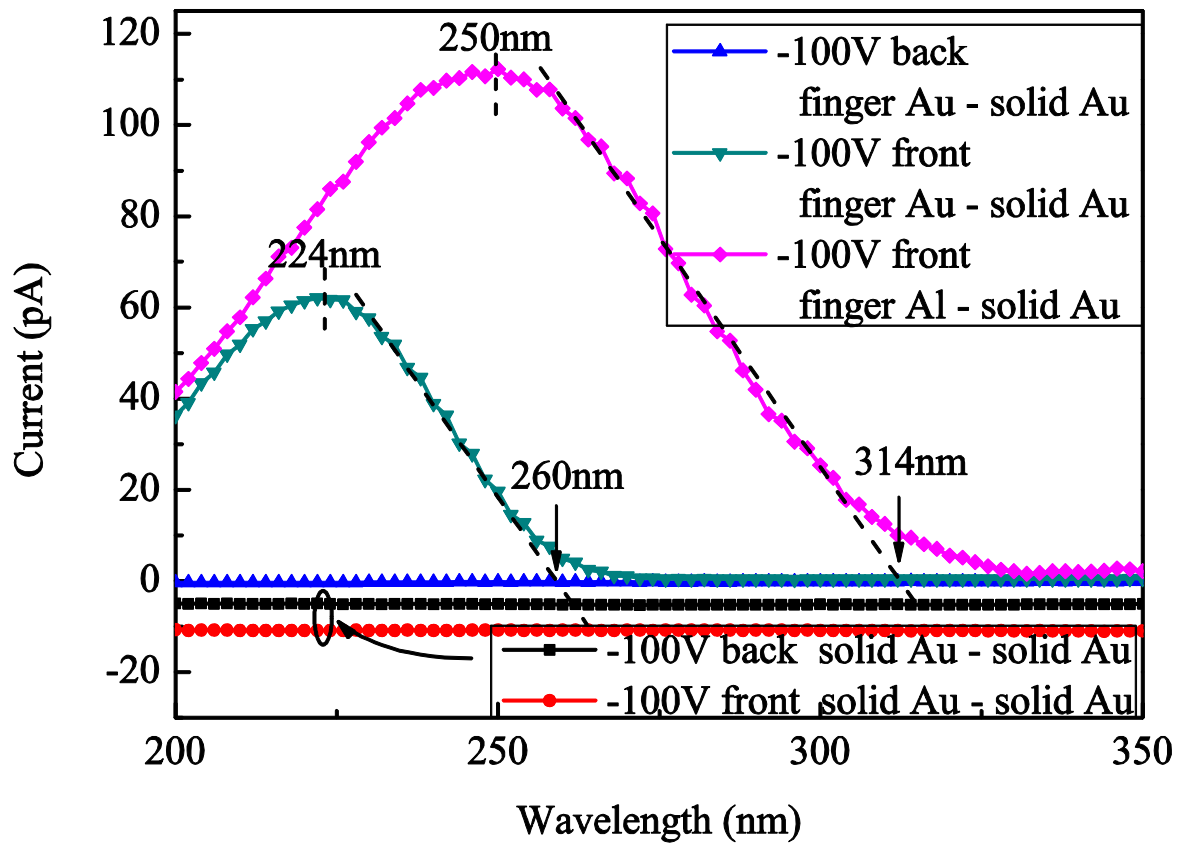




\section{Figure 3.}

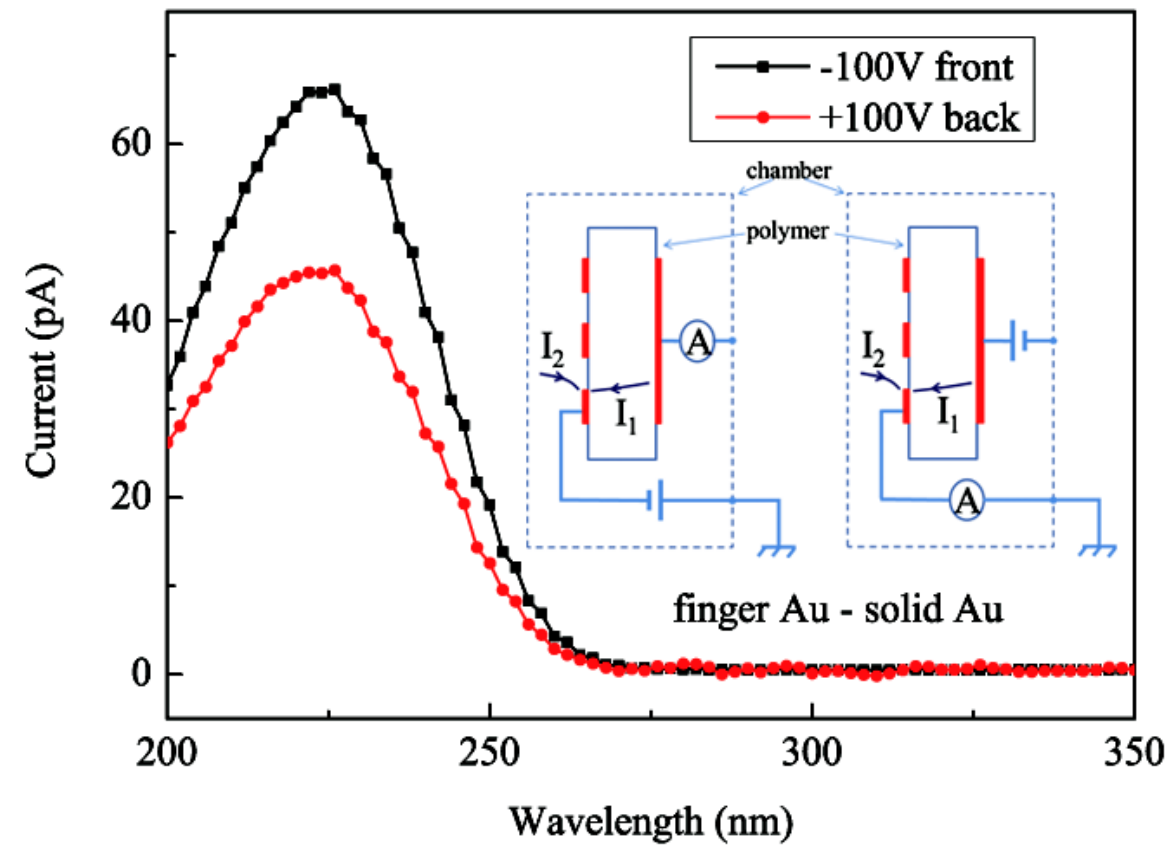




\section{Figure 4.}

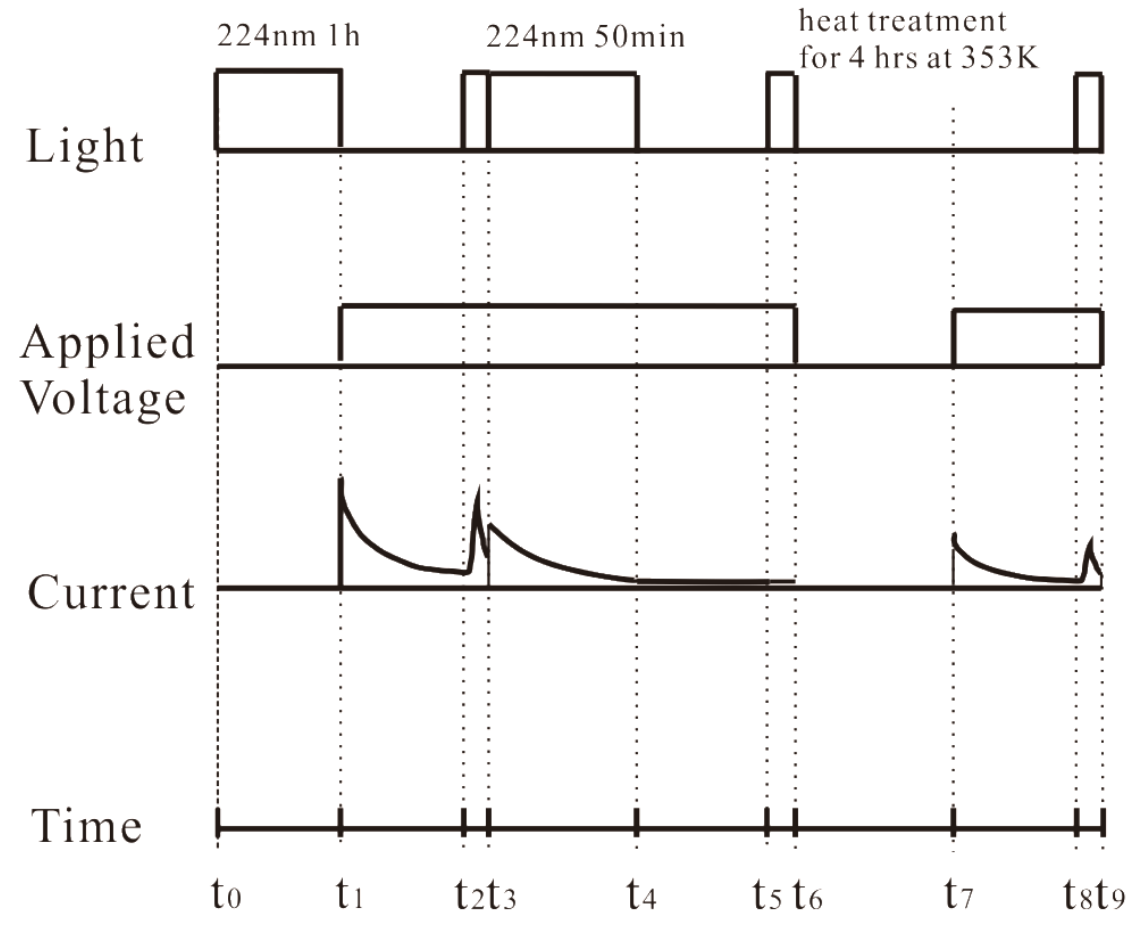




\section{Figure 5.}

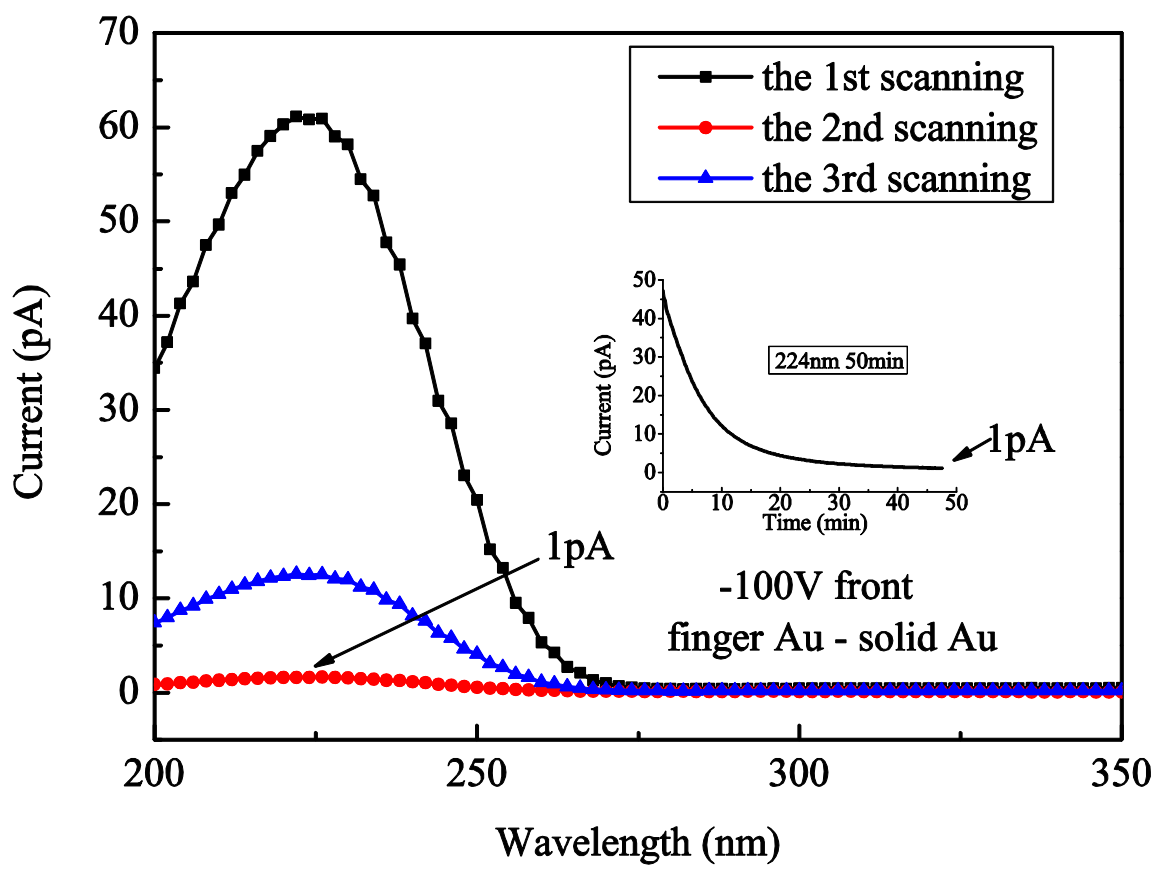




\section{Figure 6.}
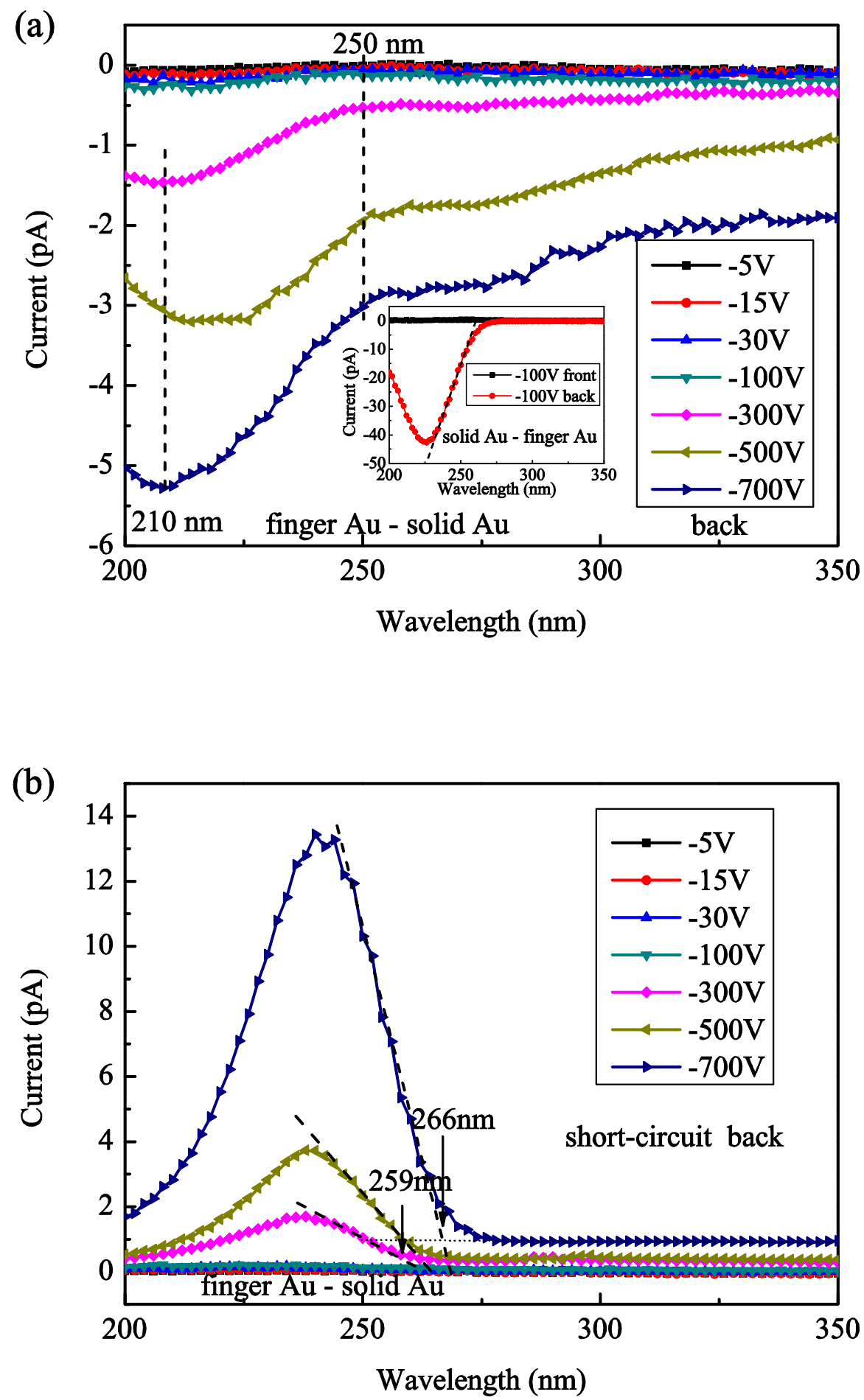


\section{Figure 6.}
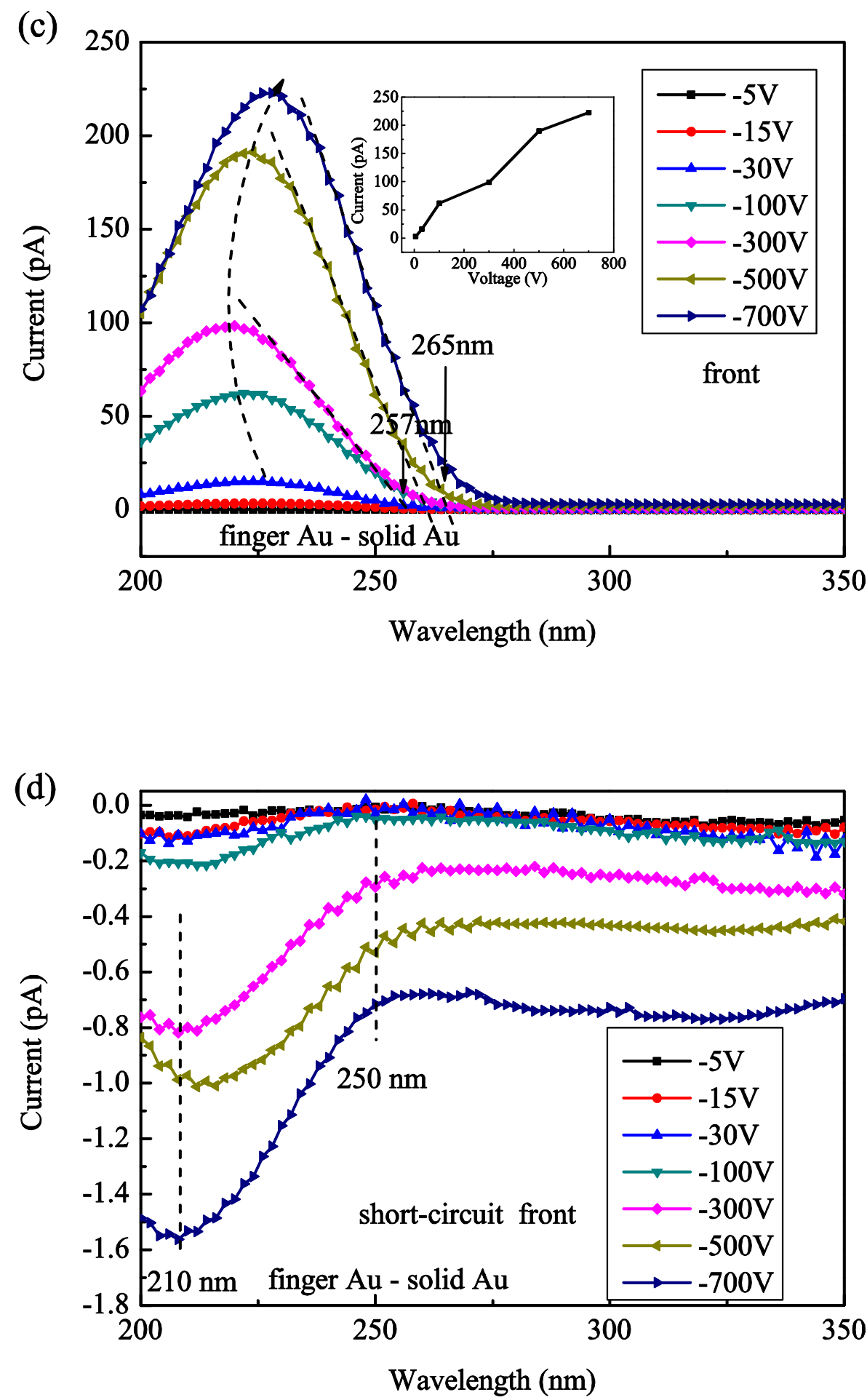


\section{Figure 7.}
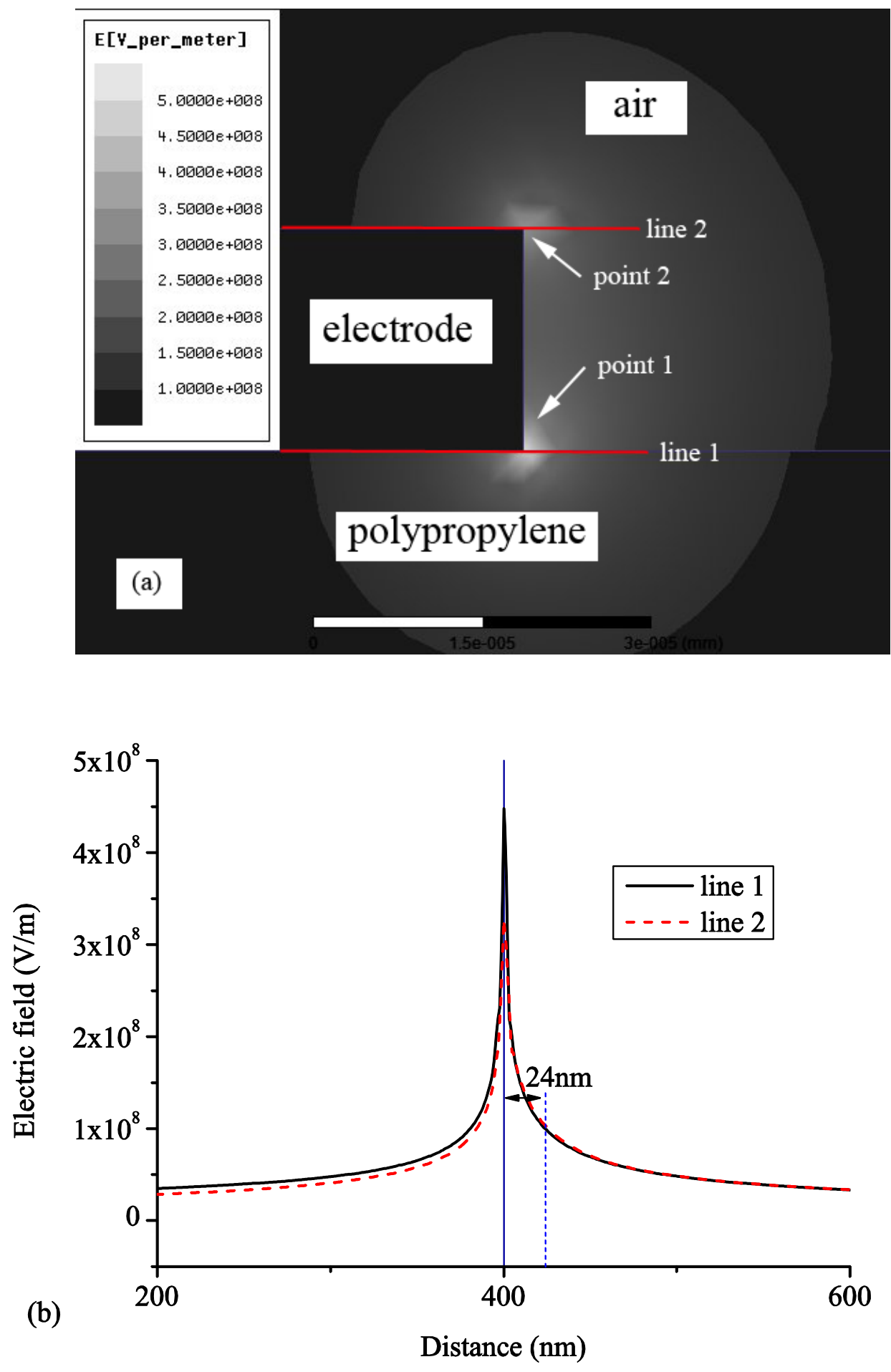


\section{Figure 8.}

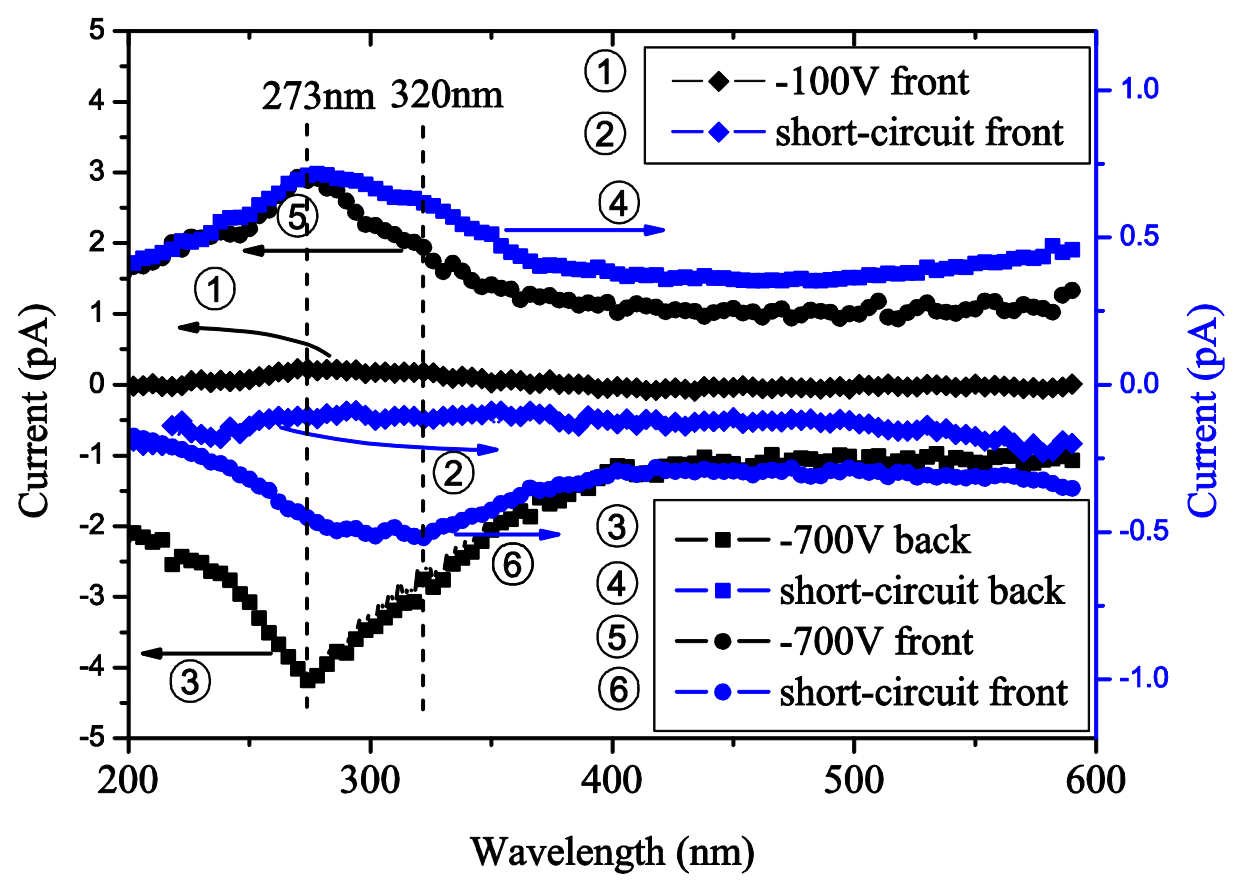

